\title{
A Divulgação Científica como Forma de Disseminação de Conhecimentos sobre Agricultura Orgânica
}

\author{
Fábio Freire Rabelo \\ Programa Stricto Sensu do Centro Universitário Plínio Leite \\ frabelo2077@ibest.com.br \\ Rose Mary Latini \\ Programa Stricto Sensu do Centro Universitário Plínio Leite \\ rmlatinieuol.com.br
}

Resumo: Este trabalho teve por objetivo compreender a estrutura e organização da agricultura orgânica, a partir do olhar dos sujeitos diretamente envolvidos com esta realidade. O cenário é uma das regiões produtoras no estado do Rio de Janeiro, a cidade de São José do Vale do Rio Preto (RJ). Utilizamos a pesquisa qualitativa, de cunho exploratório e descritivo, tendo como sujeitos produtores de orgânicos e outros atores sociais da região. Para levantamento de dados utilizamos conversas informais e entrevistas semi-estruturadas. Os resultados apontam que conhecimentos sobre as formas de manejo na agricultura, mercado, meio ambiente e sociedade são conhecimentos que podem contribuir não somente para o entendimento desta forma de produção, mas também para a formação de uma consciência socioambiental. Assim, a divulgação científica, pode contribuir para o entendimento sobre a agricultura orgânica, sua relação com a saúde e o ambiente, além de proporcionar aos interessados a ampliação de seus conhecimentos e sua interação com o meio natural.

Palavras-chave: Agricultura Orgânica. Educação Ambiental. Divulgação Cientifica.

\section{Science popularization as knowledge dissemination about organic agriculture}

\begin{abstract}
The aim of this work is to understand the structure and organization of organic agriculture, from look of subjects directly involved with this reality, organic producers and other actors of São José do Vale do Rio Preto city, one of the producing regions in the state of Rio de Janeiro. The qualitative research, exploratory and descriptive, was use. For data collections were used informal conversations and semi-structured interviews. The results show that knowledge about the means of management in agriculture, market, environment and society are knowledge that can contribute not only to understanding this production form, but also a social and environmental formation conscience. The science
\end{abstract}


popularization can contribute to the understanding of organic agriculture, its relation to health and the environment, to expand knowledge about topic and the people interaction with the natural environment.

Keywords: Organic Agriculture. Environmental Education. Science Popularization.

\section{Introdução}

A proposta de utilização dos recursos naturais de forma eficiente trouxe para a agricultura a ideia de sustentabilidade, que se traduz em uma maneira diferente de realizar o manejo do solo, trazendo benefícios para o agricultor, para a natureza e a sociedade, quebrando paradigmas sobre os cultivos tradicionais ou convencionais. Uma das práticas encontradas foi o desenvolvimento de uma agricultura baseada em produção ecológica de alimentos. Chegou-se assim a uma ideologia de utilização inteligente dos recursos naturais, que se denominou “agricultura sustentável”. Segundo estudos da FAO (1989) “o objetivo de uma agricultura sustentável deve ser o de envolver o manejo eficiente dos recursos disponíveis, mantendo a produção nos níveis necessários para satisfazer às crescentes aspirações de uma crescente população, sem degradar o meio ambiente" (Paterniani, 2001 p. 304).

O termo agricultura orgânica, utilizado hoje, partiu de alguns movimentos criados em 1920 que repudiavam a ideia de utilização de adubação química, onde só se permitia a utilização de matéria orgânica como fator de propulsão nesta atividade, com o intuito de melhorar as condições do solo e a saúde das plantas. Estes movimentos seguiram diferentes vertentes tais como: a agricultura biodinâmica, a orgânica propriamente dita, biológica e natural. Posteriormente, outras designações foram utilizadas para os cultivos acima, como: método Lemaire-Boucher, permacultura, ecológica, ecologicamente apropriada, regenerativa, renovável, dentre outras (Saminez et alii, 2007). Estas vertentes, embora houvessem se desenvolvido em diferentes momentos e possuíssem características diferentes, possuem objetivos em comum: dar sustentabilidade ao meio ambiente e proporcionar saúde às pessoas. Mas, foi em 1970 que o conjunto destas culturas passou a chamar-se agricultura alternativa, na busca de dar opção ao agricultor convencional (que utiliza fertilizantes químicos) migrar para uma cultura ecologicamente correta.

Neste contexto, a agricultura orgânica como um tipo de agricultura sustentável se torna uma contribuição importante para a busca de um equilíbrio ambiental. Esta não utiliza agrotóxicos ou produtos químicos similares, que são substituídos por matéria orgânica para o manejo do solo, trazendo benefícios para o ambiente e para a saúde.

No Brasil, o sistema de agricultura orgânica ocorreu somente a partir de 1992, principalmente através da agricultura familiar. Inicialmente a proposta visava somente o meio natural, logo após, passou a ter uma nova conotação que levava em consideração outras variáveis como "o desenvolvimento da agricultura de forma economicamente viável, socialmente justa e ambientalmente correta" (Mazzoleni e Nogueira, 2006). 
Um dos problemas encontrados na agricultura orgânica é a divulgação de sua cultura, tanto nas questões relativas à sua produção quanto ao consumo. Atualmente no Brasil a maior parte da oferta é acessível somente a uma pequena parcela da sociedade, não somente em razão de custos, ainda elevados, mas também por desconhecimento ou conhecimentos de senso comum, tanto do agricultor como do consumidor. O primeiro porque desconhece ou possui informações pouco fundamentadas a respeito do assunto e da inserção dos produtos no mercado consumidor. E, o segundo grupo, por ignorar as vantagens de um produto com tais características para a sociedade.

Assim, a divulgação científica pode contribuir com propostas para a disseminação de conhecimentos científicos que propiciem através da sua aquisição mais qualidade ambiental e compromisso para a sociedade. Desta forma, abre espaço para se discutir assuntos que permeiam a relação entre ciência, tecnologia, sociedade e ambiente sendo, um dos seus objetivos, a busca da desmistificação de conhecimentos de caráter duvidoso ou impreciso ao público em geral (Chassot, 2003, p. 91).

Entretanto, para se discutir problemas socioambientais é necessário que o cidadão esteja cientificamente alfabetizado, ou seja, fazendo uma leitura do mundo de forma a obter compreensão da realidade, além de estar consciente de seu papel social (Guimarães e Vasconcellos, 2006 p. 153).

Para Chassot (2003, p. 91), a característica principal para o indivíduo estar alfabetizado cientificamente "é saber ler a linguagem em que está escrita a natureza", pois desta forma poderá entender a si mesmo, assim como o ambiente que o cerca.

Tal ação requer um conhecimento da realidade, não como um somatório de dados, mas como a junção destes dados acrescidos da percepção que os sujeitos têm desta realidade. Desta forma, nos reportamos à "realidade concreta", conforme definida por Freire (1986, p.35).

A realidade concreta é algo mais que fatos ou dados tomados mais ou menos em si mesmos. Ela é todos esses fatos e todos esses dados e mais a percepção que deles esteja tendo a população neles envolvida. Assim, a realidade concreta se dá a mim na relação dialética entre objetividade e subjetividade.

Assim, com o objetivo de conhecer um pouco mais sobre a agricultura orgânica este estudo buscou uma aproximação com uma região produtora de orgânicos, São José do Vale do Rio Preto, no Rio de Janeiro, com a finalidade de compreender a estrutura e organização deste tipo de agricultura a partir do olhar dos sujeitos diretamente envolvidos com esta realidade.

O estudo aqui apresentado é parte da dissertação de mestrado do autor que teve como objetivo a elaboração de uma proposta de divulgação científica em um espaço não formal de ensino Acreditamos que a educação ambiental e a divulgação científica apresentamse como meios capazes de contribuir para a construção de conhecimentos e a difusão de informações relevantes para a sociedade - tanto em espaço formal de ensino quanto em 
espaço não formal - sobre a produção e o consumo de produtos orgânicos, afim de que esta possa, conscientemente, fazer suas escolhas.

\title{
Educação Ambiental e Divulgação Científica
}

Tratada como um processo de aprendizado permanente, baseado no respeito a todas as formas de vida, a Educação Ambiental pode ser compreendida como uma estratégia para a construção de uma sociedade sustentável e ecologicamente equilibradas, pois sua responsabilidade abrange o individual e o coletivo (Tozzoni-Reis, 2006 p. 96). Segundo Loureiro (2004), a Educação Ambiental "busca a transformação social fundada no diálogo, no exercício da cidadania, na superação das formas capitalistas de dominação, na compreensão da complexidade do mundo e da totalidade da vida". Assim, o processo de conscientização nas práticas de Educação Ambiental aponta para uma compreensão mais crítica da realidade e do homem e do seu papel no mundo e de sua inserção na história. (Freire, 1980, p.25 apud Tozzoni-Reis, 2006 p. 106).

Para Tozzoni-Reis (2004, p. 147 apud Tozzoni-Reis, 2006, p. 97)

\begin{abstract}
A Educação Ambiental é dimensão da educação, é atividade intencional da prática social, que imprime ao desenvolvimento individual um caráter social em sua relação com a natureza e com os outros seres humanos, com o objetivo de potencializar esta atividade humana, tornando-a mais plena de prática social e de ética ambiental.
\end{abstract}

Jacobi (2003) complementa que a Educação Ambiental tem por objetivo combater a degradação ambiental, neste contex to o homem deve participar ativamente através de ações para desenvolvimento sustentável. Segundo Campos (2006), a Educação Ambiental deve ser vista como uma possibilidade de se realizar uma educação crítica e transformadora e não somente com os desafios atuais de proteção ambiental. Sua atuação deve fomentar valores e atitudes que possam melhorar efetivamente a utilização dos recursos sociais e naturais, transformando em processos democráticos.

Reconhecendo o caráter fundamental da educação na construção de valores, na compreensão coletiva da complexidade ambiental e na ação social, o Tratado de Educação Ambiental para Sociedades Sustentáveis e Responsabilidade Global, firmado durante a Eco-92 (Unesco, 1992), aponta princípios para o estabelecimento de sociedades sustentáveis. Ressaltamos aqui, um dos itens deste plano de ação:

Fazer circular informações sobre o saber e a memória populares; e sobre iniciativas e tecnologias apropriadas ao uso dos recursos naturais.

A ciência vista como linguagem facilitadora para a leitura do mundo natural, vem ganhando espaço para discussão sobre a sua importância para a realização da inclusão social nos diferentes espaços de ensino (Guimarães e Vasconcellos, 2006, p. 92). Assim, 
a divulgação científica vem se fixando no meio social com o intuito de estimular uma apropriação de conhecimentos e realizar a inclusão social como forma de promoção de cidadania (Marandino, 2005, p. 162).

Na divulgação de ciência em espaços não formais, a questão ambiental também vem ganhando destaque, com o intuito de transformar o ser humano em um ator consciente no que tange a sustentabilidade ambiental.

Os espaços não formais de ensino podem atuar de forma a complementar a disseminação de conhecimentos científicos para um indivíduo ou grupo social, podendo apresentar informações através de textos, multimídia, dentre outras tecnologias, gerando o saber científico (op cit p. 163).

Para Guimarães e Vasconcelos (2006, p. 157), a educação não formal possui uma maior flexibilidade com relação ao tempo e sua contribuição científica e humanística não tem a intenção de suprir deficiências do sistema formal, mas sim agir como um complemento que estimule a ampliação do conhecimento através da interdisciplinaridade e contextualização.

Ainda que incipiente, os espaços não formais para a formação de conhecimentos sobre agricultura orgânica já existem no Brasil (Cidade Junior, 2008), em função de sua importância no cenário atual, onde questões pertinentes à sustentabilidade têm obtido ênfase em todas as esferas sociais, através da disseminação da cultura e da minimização dos prejuízos causados ao meio ambiente.

Tornar o conhecimento científico difundido por toda a sociedade ainda é um desafio, pois "se assume como necessidade ética a importância de levar as informações produzidas pela ciência e tecnologia a um público cada vez mais amplo, como instrumento de cidadania" (Díaz, 1999 apud Marandino, 2005, p. 162).

\section{A aproximação com a produção de orgânicos}

Utilizamos a pesquisa qualitativa, de cunho exploratório e descritivo, por tratar-se do tipo de pesquisa mais apropriada para o estudo. Esta utiliza métodos e técnicas, para levantar dados sobre o real a partir de significados e concepções identificadas. (Lüdke e André, 1986). Para levantamento de dados utilizamos a observação, conversas informais e entrevistas semi-estruturadas. Estes instrumentos de coleta de dados são característicos da pesquisa qualitativa (Minayo e Deslandes, 2008).

Assim, participaram desta pesquisa produtores de orgânicos e outros atores sociais da região de São José do Vale do Rio Preto. Dentre eles, um professor e jornalista, o qual tem um trabalho na disseminação de conhecimentos para os agricultores orgânicos locais e/ou agricultores convencionais que estão dispostos a realizar a transição para a cultura orgânica, no intuito de melhorar as condições produtivas e a coordenadora local, responsável pela certificação ABIO (Associação de Agricultores Biológicos do Estado do Rio de Janeiro). Esta realiza as auditorias para a certificação ou somente a manutenção da mesma, o seu trabalho corresponde a liberação ou não do selo utilizado nas embalagens dos produtos orgânicos para sua comercialização. A entrevista com a coordenadora contribuiu para o 
entendimento de todo o processo de certificação.

A região de São José do Vale do Rio Preto foi escolhida para este estudo, devido à sua representatividade na produção de orgânicos no Estado do Rio de Janeiro, pois é uma das maiores regiões produtoras do estado. Dentre o universo de agricultores orgânicos de pequeno, médio e grande porte, dependendo de sua estrutura produtiva e área destinada ao plantio, estes exercem atividades de subsistência e destinam ao mercado a maior parte da produção. Segundo relato dos sujeitos, a maior parte de sua produção não é absorvida pelo mercado doméstico, pois são vendidas para regiões com maior potencial de consumo como São Paulo, Minas Gerais e somente parte para o Rio de Janeiro (capital).

A produção de orgânicos da região é bastante diversificada, onde podemos destacar os seguintes itens: chuchu, abobrinha, jiló, berinjela, tomatinho pêra, repolho, folhagens em geral, cenoura e beterraba, que nesta modalidade são cultivados através da agricultura familiar. Já as frutas e aves têm seu cultivo e criação, respectivamente, em fazendas com maior espaço físico. Além destes, está em fase de experimentação o cultivo de maça orgânica.

A maior parte dos agricultores da região, sejam eles orgânicos ou não, não possuem estrutura logística de transportes, desta forma dependem de atravessadores que levam a produção disponível para os grandes mercados e centros de distribuições.

A cultura orgânica requer o domínio do conhecimento e técnica, o agricultor precisa ter ciência sobre os calendários sazonais e principalmente, saber o que vai plantar. De acordo com informações obtidas as duas formas de produção mais utilizadas na região são: consórcio de culturas ${ }^{1}$ e curva de nível ${ }^{2}$.

A fim de obter um cronograma e algumas definições sobre as atividades anuais na região existem alguns encontros realizados com alguns dos agricultores orgânicos na Horta Orgânica ${ }^{3}$ Estas reuniões são mediadas pela coordenadora responsável pela certificação (ABIO) para discutir com o grupo os principais problemas, possíveis soluções e oportunidades. Além disso, para não obter a desvalorização dos alimentos em razão de uma produção maciça de um mesmo tipo, levando a diminuição do preço em função da oferta maior que a demanda. Após as discussões são dadas sugestões para cada agricultor, mediante prévia análise de suas terras (tamanho, tipo de solo e etc.), melhorando sua produção, obtendo variedade e quantidade dentro de uma curva de demanda, a qual é economicamente interessante para a região.

Para o jornalista, sujeito desta pesquisa, SJVRP e as regiões adjacentes não seriam uma referência em agricultura orgânica se não houvesse uma estrutura e organização por parte dos agricultores. A Horta Orgânica tem grande influência nesse processo, dando suporte e administrando os interesses dos agricultores associados.

Além do levantamento destes dados realizamos uma entrevista com três dos agricultores, onde dois são de pequeno porte (até 2 hectares) e um de grande porte (20 hectares). A escolha dos agricultores justifica-se pela acessibilidade e experiência que os mesmos possuem nesta atividade. Participaram deste estudo os seguintes sujeitos: o primeiro é um agricultor de pequeno porte da cidade de SJVRP. Viveu sempre da agricultura e foi o pioneiro na adoção do modelo orgânico na região, a partir de 1996. O segundo é agricultor 
de pequeno porte da cidade de Sapucaia, oriundo da capital do RJ, e mudou-se para esta cidade há 15 anos, inicialmente trabalhou com lavouras convencionais e 4 anos depois aderiu à agricultura orgânica. $\mathrm{O}$ terceiro é um agricultor de grande porte, foi empresário na cidade do RJ e após se aposentar migrou para SJVRP buscando tranquilidade e qualidade de vida. Já iniciou as atividades com a agricultura orgânica.

Estas entrevistas ocorreram no período de setembro a novembro de 2008 e tiveram por finalidade captar a experiência na atividade agrícola. Algumas perguntas nortearam este momento, sendo que o entrevistado teve liberdade para se expressar livremente, foram elas: o que motivou a adoção da agricultura orgânica? Quais são as principais desvantagens da agricultura orgânica local? Como é realizado o processo de certificação? Como é a demanda para estes produtos? Qual é sua expectativa da produção de orgânico para os próximos anos?

Nas entrevistas com os agricultores procuramos também entender sobre os processos de cultura orgânica, sua importância no campo e como estes trabalham para atender o mercado consumidor.

À medida que foram respondidas, o pesquisador foi transcrevendo as falas buscando desta forma, compreender a estrutura e a organização da produção de orgânicos. Foram anotadas algumas particularidades de cada agricultor, como é o caso do primeiro sujeito, que foi o precursor da cultura orgânica local, além de problemas e oportunidades comuns a todos.

\section{Resultados e Discussão}

Como o conteúdo de uma comunicação permite ao pesquisador várias interpretações, "dos quais são construídos significados em relação aos fenômenos investigados" (Moraes, 2003, p.194) utilizamos a análise textual discursiva. Assim, na interpretação das falas, procuramos elementos que permitissem o entendimento de como a agricultura orgânica se constitui na prática, possibilitando um melhor entendimento sobre as questões pertinentes aos produtos orgânicos na região de estudo.

Em relação à motivação dos agricultores na adoção da agricultura orgânica, as falas sugerem que esta opção foi feita na busca de uma melhor qualidade de vida e para os agricultores anteriormente convencionais, pelo entendimento dos danos causados à saúde pelos agrotóxicos. A seguir são apresentadas as falas:

Agricultor 1 - o fato de dar melhor qualidade de vida para a família, pois quando trabalhava em lavoura convencional, se obrigava a trancar sua esposa e filhos em casa para minimizar o contato com agrotóxicos;

Agricultor 2 - uma vez por semana ao pulverizar a lavoura, negociava com a direção de uma escola próxima para que as aulas fossem suspensas, para que as crianças e professores não tivessem riscos de intoxicação, optando posteriormente em seguir sua consciência ambiental e mudando para a agricultura orgânica; 
Agricultor 3 - iniciou suas atividades com agricultura orgânica, saindo da "cidade grande" e buscando qualidade de vida para ele, para a família e sociedade, além de proporcionar melhorias ao meio ambiente.

Percebemos em todas as falas que a adoção desta forma de produção está associada, em primeiro lugar, à melhoria da saúde dos sujeitos diretamente ligados à produção de alimentos só para depois se pensar na melhoria ambiente. A visão dicotômica entre homem e ambiente e entre o individual e o coletivo precisa ser superada se temos como objetivo buscar uma melhor maneira de nos relacionarmos com a natureza.

As duas primeiras falas apontam para os danos percebidos pelos agricultores pelo uso de adubos químicos. Estes já haviam sido repudiados pelos movimentos de 1920, onde somente era permitida a utilização de matéria orgânica, primando desta forma pela preservação ambiental, a biodiversidade, os ciclos biológicos e a qualidade de vida do homem, que são questões importantes para acelerar o desenvolvimento da agricultura orgânica. A última fala é de um agricultor que já iniciou suas atividades diretamente na região com a agricultura orgânica.

Um estudo realizado no Paraná mostra que o custo elevado de insumos químicos na produção convencional, é um dos fatores que impactam na migração para a cultura orgânica. Desta forma, tornam-se os custos mais reduzidos para o cultivo do orgânico, mesmo em função do pagamento da certificação, além da crescente demanda dos consumidores e a busca dos melhores sabores existentes nos produtos orgânicos (Schoenhals et al, 2009).

Considerando que todos na região reconhecem as vantagens da agricultura orgânica, questionamos os agricultores sobre as desvantagens deste tipo de agricultura:

Agricultor 1 - não existe incentivo da prefeitura local, a produção é muito menor, pois o risco de pragas é muito maior, danificando boa parte da produção;

Agricultor 2 - a questão dos atravessadores desestimula os produtores orgânicos, em função da diminuição dos volumes transportados, onde a cobrança é de $\mathrm{R} \$ 0,50$ à $\mathrm{R} \$ 1,00$ por volume, desta forma, a preferência é sempre dos produtores convencionais, além disso, existem ameaças por parte dos atravessadores de não buscar os produtos orgânicos em razão da questão da dependência de transportes, onde muitos produtores orgânicos acabam se rendendo ao retorno da cultura tradicional;

Agricultor 3 - a demanda por estes produtos ainda é baixa e desta forma, quando temos muita produção de determinados itens e o mercado não absorve, somos obrigados a vendê-los como convencional e assim, depreciamos nossos produtos.

Em uma das falas, a falta de "incentivo por parte da prefeitura" pode apontar para ausência de políticas públicas no desenvolvimento deste tipo de agricultura. Além disso, a demanda ainda é pequena por parte da sociedade, que junto a outras dificuldades, característica deste tipo de produção, como "maior risco de pragas", denotam a fragilidade da agricultura orgânica na região, que mesmo assim ainda desponta como área de referência em produção de orgânicos no Rio de Janeiro. 
Outra questão apontada é a presença de atravessadores que, juntamente com os problemas discutidos acima, dificultam, ainda mais, a chegada dos produtos para a comercialização e distribuição deste tipo de cultura.

A falta de políticas governamentais, segundo Lima (2005), também é uma realidade no nordeste brasileiro, onde produtores com instalações de 5 a 30 hectares ficam fora das políticas de programas de incentivo, além dos custos elevados para certificação.

Para um dos sujeitos da pesquisa, as principais desvantagens do produto orgânico são a presença de algum dano na aparência do produto (casca), por causa do ataque de pragas e insetos; seu tamanho menor comparado ao convencional, em função de um cultivo natural, o qual não estimula seu crescimento; além do preço que é vendido ao consumidor.

Em relação ao processo de certificação, procuramos inicialmente a coordenadora responsável pela certificação na região, que relatou como é o processo realizado nesta produção. Segundo a coordenadora, o processo começa por iniciativa do próprio agricultor em realizar a transição de culturas ou mesmo por já iniciar as atividades com a cultura orgânica.

Existem algumas análises que devem ser realizadas, como a microbiológica no solo para detectar algum tipo de fertilizante existente, caso o terreno esteja com presença de contaminação por agrotóxico, o mesmo deve passar de 2 a 3 anos sem receber nenhum tipo de agrotóxico. A água que irriga a lavoura também é um fato importante para análise, que neste caso tem sua origem investigada, pois caso algum agricultor convencional a utilize de um rio ou córrego, antes da mesma chegar à propriedade orgânica, pode existir riscos de contaminação.

Para a certificação também é necessário que todos os filhos de agricultores estejam matriculados na escola, que não haja esgoto a céu aberto na propriedade, a não existência de exploração infantil ou trabalho escravo, invasão de áreas protegidas, além de não existir nenhum fato que implique em danos ao meio ambiente.

No momento da auditoria é importante que seja verificado se o agricultor utiliza somente adubação natural através de substrato (composto natural de matérias-primas orgânicas, como: restos de vegetais e animais), que nutre o solo de maneira não tóxica. Além disso, existe o momento póscolheita, verifica-se se os produtos orgânicos estão sendo transportados junto com os convencionais, sem nenhum tipo de separação, ou mesmo se os orgânicos estão armazenados em caixas de madeira, onde nesta situação só é permitida se existir a certificação desta, nos demais casos a armazenagem deve ser feita em caixas plásticas.

Estes são alguns procedimentos básicos para a certificação, além do pagamento anual de uma taxa e a auditoria é realizada semestralmente sem que previamente o agricultor seja avisado.

Assim, em relação à pergunta aos agricultores tivemos relatos de forma unânime sobre a importância das questões relativas a certificação, como forma de segurança e valorização 
do seu trabalho. Paralelamente, os agricultores 1 e 2 fizeram uma crítica com relação ao valor da taxa de manutenção da certificação, que julgam ser alta e, por vezes, desestimula alguns agricultores a aderirem à cultura de orgânicos.

A certificação é a conformidade do processo da cultura orgânica, pois dá garantia a quem vende e a quem compra, em função de seu grau de conformidade que é apresentada através de um selo sob a chancela da certificadora, trazendo ônus ao agricultor, que por vezes, desiste do processo. Segundo a Lei 10.831/2003, que dispõe sobre a agricultura orgânica e dá outras providências, as certificadoras devem se credenciar no Ministério da Agricultura, Pecuária e Abastecimento-MAPA (Saminês, 2007). O produtor, por sua vez, poderá mudar de certificadora, em qualquer tempo, pois é livre para buscar o mecanismo de avaliação mais adequado à sua realidade.

A certificadora passa a realizar inspeções no mínimo duas vezes ao ano, onde são analisados relatórios criteriosos, com suas normas próprias seguindo o regulamento oficial. Segundo Mazzoleni e Nogueira (2006), a certificação é uma variável de controle que indica aptidão e qualificação de quem a utiliza diante do sistema orgânico. A certificação pode ainda minimizar despesas em função de uma melhor adequação e eficiência no manejo da terra, utilizando tecnologias mais apropriadas, desta forma, melhora-se a produtividade e possibilitará a prática de um melhor preço de venda.

O conceito de sustentabilidade ficou em evidência e o mercado está aceitando cada vez mais o produto orgânico como uma tendência de um meio de vida mais saudável. Assim, a certificação é uma forma de identificação deste tipo de produto (Saminês, 2007).

Desta forma, quando o agricultor introduz um produto orgânico no mercado tem vantagens sobre o convencional, pois cada vez mais o consumidor busca produtos que envolvam atributos como melhoria da saúde, justiça social e meio ambiente, principalmente quando há competitividade nos preços. Outra questão importante é a preferência dada ao orgânico por instituição como escolas, hospitais, além do programa de Aquisições do Governo Federal (AGF), fato que submete o orgânico a uma valorização de cerca de $30 \%$ comparado ao convencional (Mazzoleni e Nogueira, 2006).

Uma característica marcante da agricultura orgânica é que se trata de atividades desenvolvidas pela agricultura familiar na condução das lavouras. A expansão da agricultura orgânica no Brasil é bem promissora, porém, é necessária uma legislação eficiente, a redução dos custos de certificação para os produtores, aumentar a comercialização dos produtos, além do apoio governamental através de políticas agrícolas e também do investimento em pesquisa, ensino e extensão (Bernardes Junior, 2008).

Quanto à demanda dos produtos orgânicos, tivemos algumas informações dos agricultores como segue:

Agricultor 1 - Nós agricultores, temos algumas especialidades na lavoura, em função do tipo de terreno e tamanho. Eu por exemplo, tenho boa parte de minha produção com folhagens, chuchu e abobrinha italiana, a demanda sempre existe, mas dependemos do apoio do governo, pois os preços chegam caros a quem compra e isso faz com 
que a gente diminua a produção, ou coloque o que sobra no mercado convencional;

Agricultor 2 - Se demanda existe, nós temos condições de atender, porque aqui na região ainda não utilizamos todo o espaço que temos, porque os orgânicos ainda têm baixo consumo se tivermos que comparar ao convencional;

Agricultor 3 - O fator principal para o aumento da demanda é o conhecimento do consumidor quanto aos benefícios da agricultura orgânica, a demanda tende a aumentar mediante a mudança nos hábitos alimentares.

Com franco desenvolvimento da agricultura orgânica na região, os agricultores expressam nestas falas, suas expectativas de crescimento em sua produção.

Agricultor 1 - Sempre acreditei no orgânico, tanto que fui o primeiro a
trabalhar com isso aqui na região, no começo, até de louco fui chamado,
mas agora muitos seguem meu exemplo. Minha expectativa é de
crescimento do orgânico, assim como tem acontecido em todos estes
anos que trabalho com o produto.

Agricultor 2 - Tenho boas expectativas, porque já estou neste trabalho há anos e a cada ano minha venda é maior e, além disso, vejo alguns vizinhos saindo da cultura convencional, eu sempre acreditei e esse fato me dá mais garantias de que esse é o caminho certo e que ainda vamos crescer muito.

Agricultor 3 - Consigo enxergar o orgânico como o alimento do futuro, falta apenas que os consumidores tenham cada vez mais conhecimento de seus benefícios, vamos crescer muito com isso, o potencial de mercado existe e minha expectativa é a melhor possível.

As duas primeiras falas denotam um otimismo sobre o mercado orgânico, através do aumento percebido da produção e pela migração de novos agricultores para esta modalidade. Outro fato importante é o incentivo em disseminar conhecimento e benefícios dos orgânicos ao consumidor, que desta forma irá aos poucos trazer resultados positivos para o crescimento deste mercado.

Estes agricultores puderam já iniciar sua cultura orgânica ou apenas migrar para ela, porém, percebe-se que a disseminação do conhecimento científico é fundamental para dar suporte ao desenvolvimento desta forma de agricultura.

A divulgação científica, neste contexto, deve ser realizada através de uma linguagem apropriada para a compreensão do mundo natural, não de forma empírica, mas de maneira criteriosa e de forma inteligível. O agricultor precisa deixar algumas crenças e passar a entender e transmitir um discurso verdadeiro e interpretando a ciência dentro de seu campo de atuação como uma produção cultural (Chassot, 2001, p. 438). 


\section{Considerações Finais}

A diversidade de técnicas agrícolas e os avanços no campo da ciência e tecnologia possibilitaram uma maior produção de alimentos, entretanto muitos foram os impactos causados ao homem e ao ambiente. Neste contexto, a produção agrícola sem a utilização de agrotóxicos ou produtos químicos desponta como um retorno histórico aos processos de cultivos, onde a agricultura orgânica tem um papel fundamental.

A região de São José do Vale do Rio Preto apresenta como principais fragilidades, a falta de políticas de incentivo ao crescimento dos agricultores orgânicos e a dificuldade de transportar mercadorias. Portanto, a instituição de políticas públicas no local poderia contribuir para o fortalecimento dos agricultores da região, resgatando para a cidade a posição de maior polo produtor de orgânicos do Rio de Janeiro.

Cientes que a divulgação científica é uma linha emergente do ensino de Ciências, procuramos com esta pesquisa contribuir para o entendimento de questões referentes à produção de orgânicos, considerando além de conhecimentos teóricos o conhecimento dos sujeitos diretamente envolvidos com a sua produção.

Acreditamos que conhecimentos sobre as formas de manejo na agricultura, mercado, meio ambiente e sociedade são conhecimentos que podem contribuir não somente para o entendimento desta forma de produção, mas também para a formação de uma consciência socioambiental. Assim, a divulgação científica, em espaços formais ou não formais de ensino, de forma simples e consciente ao público em geral, contribuirá para o entendimento sobre a agricultura orgânica, sua relação com a saúde e o meio ambiente, além de proporcionar aos interessados a ampliação de seus conhecimentos e sua interação com o meio natural.

Esperamos que a divulgação de informações possa contribuir para uma aproximação do homem com a natureza, a partir da oferta de produtos saudáveis com a inexistência de contaminantes, preservando assim o meio ambiente e a saúde do agricultor e do consumidor. 


\section{Notas}

1 É a utilização do solo de maneira otimizada, através do cultivo de várias espécies: com uma boa oferta de milho verde de novembro a maio, pode-se conciliar com a produção de jiló de janeiro à setembro, desta forma, em abril, mês que precede a colheita do milho verde, o segundo item já poderá ser plantado. Além disso, neste tipo de cultura, o solo absorve muito mais nutrientes, o que possibilitará uma melhor qualidade ao produto após a colheita.

2 Habitualmente usada na produção orgânica, principalmente nas áreas com maior declínio. Consiste em dispor a plantação com cavidades e em filas horizontais, a fim de evitar que os nutrientes encontrados no solo sejam levados pelas chuvas até as planícies, de forma a não comprometer o desenvolvimento do plantio.

3 Horta Orgânica é a associação dos agricultores orgânicos de São José do Vale do Rio Preto e adjacências, a qual tem a função de contribuir para o desenvolvimento da agricultura orgânica local através de orientação técnica e abertura de novos mercados.

\section{Referências}

Bernardes Junior, H. (2008). Implementação do banco de dados do serviço consulte especialistas de agricultura orgânica da Universidade do Campo. Dissertação de Mestrado em Tecnologia de alimentos, UFPR.

Campos, R. A. (2006). A educação ambiental e a formação do educador crítico: estudo de caso em uma escola da rede pública. Dissertação de Mestrado em Educação, PUCCampinas.

Chassot, A. (2001). Alfabetização científica: questões e desafios para a educação. Unijuí, Ijuí.

Chassot, A. (2003). Alfabetização científica: uma possibilidade para a inclusão social. Revista Brasileira de Educação. (22), 89-100.

Cidade Junior, H. A. (2008). A agricultura orgânica na região metropolitana de Curitiba: fatores que afetam seu desenvolvimento. Dissertação de Mestrado em Agricultura, UFPR

Freire, P. (1986). Criando métodos de pesquisa alternativa: aprendendo a fazê-la melhor através da ação. In: Brandão, C.R. (org.). Pesquisa Participante. Brasiliense, São Paulo.

Guimarães, M. e Vasconcellos, M. M. N. (2006). Relações entre educação ambiental e educação em ciências na complementaridade dos espaços formais e não formais de educação. Educar, (27), 147-162. Editora UFPR, Curitiba.

Jacobi, P. (2003). Educação Ambiental, cidadania e sustentabilidade. Cadernos de Pesquisa (118), 189- 205.

Lima, J. S. (2005). Produção Brasileira tem reconhecimento internacional. Ciência e Cultura. 57(3).

Loureiro, C.F.B. (2004). Trajetória e fundamentos da educação ambiental. Cortez, São Paulo.

Lüdke, M. e A. M. E. D. A. (1986). Pesquisa em educação: abordagens qualitativas.EPU, São Paulo. 
Marandino, M. (2005). A pesquisa educacional e a produção de saberes nos museus de ciências. História, Ciência, Saúde - Manguinhos. (12), 161-181..

Mazzoleni, E. M. e Nogueira, J. M. (2006). Agricultura orgânica: características básicas de seu produtor. Revista de Economia e Sociologia Rural. 44 (2).

Moraes, R. (2003). Uma tempestade de luz: A compreensão possibilitada pela análise textual discursiva. Ciência e Educação. 9 (2), 191-211.

Minayo, M. C. S. e Deslandes, S. F. (2008). Análise da implantação do sistema de atendimento pré-hospitalar móvel em cinco cidades brasileiras. Caderno de Saúde Pública. 24 (8), 1877-1886.

Paterniani, E. (2001). Agricultura Sustentável nos trópicos. Estudos Avançados. 15(43) 303-326.

Saminêz, T. C. O; Dias, R. P; Nobre, F. G. A; Gonçalves, J. R. A e Mattar, R. G. H. (2007). Princípios norteadores. In: Produção orgânica de hortaliças: o produtor pergunta a Embrapa responde. Editores técnicos: Gilmar Paulo Henz, Flávia Aparecida de Alcântara, Francisco Vilela Resende. - Brasília, DF: Embrapa Informação Tecnológica.

Saminêz, T. C. O; Dias, R. P; Nobre, F. G. A; Gonçalves, J. R. A e Mattar, R. G. H. (2007). Legislação e certificação. In: Produção orgânica de hortaliças: o produtor pergunta, a Embrapa responde. Editores técnicos: Gilmar Paulo Henz, Flávia Aparecida de Alcântara, Francisco Vilela Resende. - Brasília, DF: Embrapa Informação Tecnológica.

Schoenhals, M; Follador, F. A. C. e Winck .C. (2009). Aspectos sociais, ambientais e econômicos da agricultura orgânica: estudo de caso em Verê-PR. Engenharia Ambiental - Espírito Santo do Pinhal. 6 (1) 269-292.

Tozzoni-Reis, M. F. C. (2006). Temas ambientais como "temas geradores": contribuições para uma metodologia educativa ambiental crítica, transformadora e emancipatória. Educar, Curitiba, (27), 93-110. Editora UFPR.

Unesco (1992). Tratado de Educação Ambiental para Sociedades Sustentáveis e Responsabilidade Global. 1992. Endereço: http://portal.mec.gov.mec.gov.br/secad/ arquivos/pdf/educaoambiental/tratado.pdf. Acesso em 22/07/2011. 